Kalpa Publications in Civil Engineering
Volume 1, 2017, Pages 450-455
$\begin{gathered}\text { ICRISET2017. International Conference on Re- } \\ \text { search and Innovations in Science, Engineering } \\ \text { \&Technology. Selected papers in Civil Engineering }\end{gathered}$

\title{
Seismic Response of Elevated Liquid Storage Steel Tank with Triple Friction Pendulum System at Base of Tower Under Near- Fault Ground Motion
}

\author{
Ankita K. Shah ${ }^{1,2,3^{*}}$ and Dr.Vijay.R.Panchal ${ }^{1+}$ \\ ${ }^{1}$ Civil and structural engineering,CHARUSAT, Changa, India \\ ${ }^{2}$ Professor and H.O.D., CHARUSAT, Changa India \\ ankitashah00718@gmail.com, vijaypanchal.cv@charusat.ac.in.
}

\begin{abstract}
In this study, the performance of elevated steel water tank with TFPS isolation under near fault ground motion is evaluated. Mathematical model of storage tank is distinct with four degree of freedom model includes tower structure, sloshing mass, isolation system and impulsive mass. TFPS provided at foundation level of tower structure. Performance of TFPS is compared with FPS using SAP 2000.
\end{abstract}

\section{Introduction}

Storage tanks of fluid are very curious structures for industries and power plants due to their variable storage level. It is necessary to provide effective technique to prevent effect of a strong external disturbance. In the past many failure of water tank has been recorded due to earthquake. As Triple Friction Pendulum System (TFPS) is derivative of Friction Pendulum System, so it may be very adequate device for controlling earthquake effect on a structure during earthquake excitation. Previous studies of the various friction pendulum isolators paying attention mainly on behavior of base-isolated structures far-off from active earthquake faults.

Shrimali and Jangid (2002) investigated performance of different isolation system for storage tank of fluid and fund that sliding type isolation more powerful then elastomeric bearing. Mlivaoglu and Dogangun (2006) anticipated simplified seismic analysis procedure for tanks. Panchal and Jangid (2008) investigated advanced VFPS, which controls isolator displacement, base shear in desirable assortment for near fault ground motion. Seleemah and Sharkway (2011) examine accuracy in 
prediction for modeling of isolated tank using SAP 2000 and 3D BASIS ME. Authors found that SAP 2000 successful in producing results as compared to 3D BASIS ME.

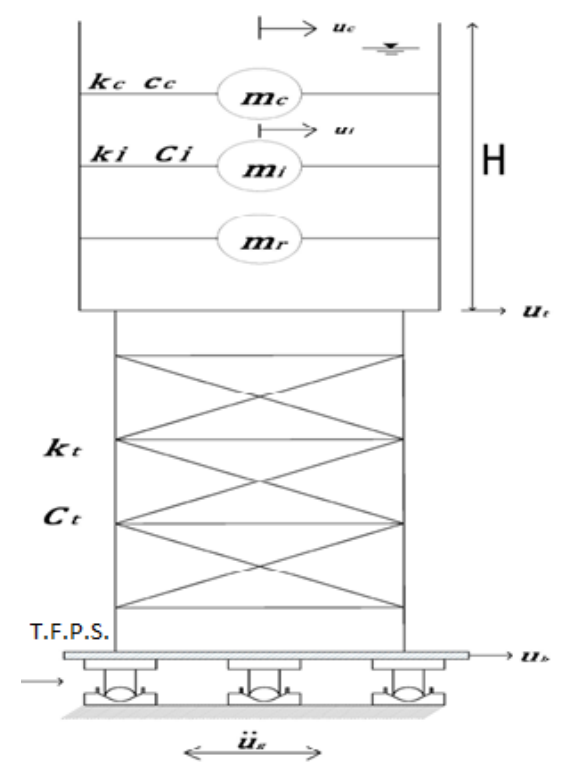

Table 1Properties of elevated tank

\begin{tabular}{|c|c|}
\hline Elements & Description \\
\hline $\begin{array}{c}\text { Aspect ratio } \\
S(H / R), H, \\
\text { Where } H \text { Height, } \\
R \text { Radius of tank }\end{array}$ & $\begin{array}{c}1.85 \\
11.3 \mathrm{~m}\end{array}$ \\
\hline $\begin{array}{c}\text { Convective mass } \\
m_{c}\end{array}$ & 346.6ton \\
\hline $\begin{array}{c}\text { Impulsive mass } \\
m_{i}\end{array}$ & 917.35ton \\
\hline $\begin{array}{c}\text { Rigid mass } \\
m_{\mathrm{r}}\end{array}$ & 1031.6ton \\
\hline Total mass & 2295.5 ton \\
\hline
\end{tabular}

Figure 1 Mathematical modeling of elevated tank

\section{Modeling of elevated tank}

The model taken for the present study shown in Fig 1, in which TFPS is provided at foundation of tower. Liquid in tank is incompressible, non-viscous and ir-rotational flow. When earthquake strikes the entire fluid mass vibrates in three specific patterns like sloshing or convective mass (i.e. top free fluid mass), impulsive mass (i.e., intermediary fluid mass swing with tank wall) and rigid mass (i.e. lower fluid mass whose movement synchronizes with tank wall). Lumped mass is referred as sloshing mass $\mathrm{mc}$, impulsive mass as mi and rigid mass as $\mathrm{m}_{\mathrm{r}}$. Thus, the system has four degrees of freedom. It is based on elevated-isolated tank under uni-directional earthquake excitation. The degrees of freedom are represented by $u_{t}$ tower structure displacement, $u_{c}$ sloshing displacement, $u_{i}$ impulsive displacement and $\mathrm{u}_{\mathrm{b}}$ isolator displacement. Equivalent stiffness and damping of tower structure, $\mathrm{k}_{\mathrm{t}}$ and ct, sloshing mass $\mathrm{k}_{\mathrm{c}}$ and $\mathrm{c}_{\mathrm{c}}$, and impulsive mass $\mathrm{k}_{\mathrm{i}}$ and $\mathrm{c}_{\mathrm{i}}$. The assumptions for modeling of tank are as follows.(1) Self weight of tank is neglected since it is very small.(2)System excited by normal component and contribution of parallel component of near fault ground motion is neglected. Calculations of mass, equivalent stiffness and damping of elevated water tank are based on methodology used in [4].The calculated parameters are shown in Table 1.

\section{Triple Friction Pendulum Isolator Calculation}

\subsection{Geometric Properties}

$$
R_{I}=R_{4}=20521.77 \mathrm{~mm} \text { or } 20.521 \mathrm{~m}
$$


$R_{2}=R_{3}=3727.89 \mathrm{~mm}$ or $3.727 \mathrm{~m}$

$h_{1}=h_{4}=936.56 \mathrm{~mm}$ or $0.936 \mathrm{~m}$

$h_{2}=h_{3}=697.83 \mathrm{~mm}$ or $0.697 \mathrm{~m}$

$d_{l}=3268 \mathrm{~mm} \quad d_{2}=468.28 \mathrm{~mm}$

$R_{\text {leff }}=R_{4 \text { eff }}=R_{l}-h_{l}=20521.77-936.56=19585.21 \mathrm{~mm}$

$R_{\text {2eff }}=R_{3 \text { eff }}=R_{2}-h_{2}=3727.89-697.83=3030.06 \mathrm{~mm}$

$d_{1} *=d_{4} *=d_{1} . R_{\text {leff }} / R_{1}=3118.85 \mathrm{~mm}$

$d_{2} *=d_{3} *=d_{2} . R_{2 e f f} / R_{2}=380.62 \mathrm{~mm}$

\subsection{Calculating Frictional Properties of the bearing}

Bearing Pressure at surfaces 1 and 4

$P=$ Load $/$ Area Here $V_{k}$ load $=2295.5$ ton

Area $A=\pi r^{2} \quad r=h_{1}+h_{4}=936.56+936.56$

$P=2.083 \mathrm{E}-04 \mathrm{ton} / \mathrm{mm}^{2}$,

$P=0.0002 \times 1450=0.302 \mathrm{ksi}, \quad 1 \mathrm{ksi}=1450 \mathrm{ton} / \mathrm{mm}^{2}$

3-Cycle Friction, $\mu=0.122-0.01 P \mu=0.118$

Adjust for high velocity $=-0.033=0.118-0.033=0.085$

(Lower bound friction)

I-cycle friction $\mu=1.2 \times 0.085=0.102$

Lower bound $\mu_{1}=\mu_{4}=0.085$

Upper bound $\mu_{1}=\mu_{4}=0.102$

Bearing Pressure at surfaces 2 and 3

$\mathrm{P}=$ Load / Area Here $\mathrm{V}_{\mathrm{k}}$ load $=2295.5$ ton

Area $A=\pi r^{2} r=h_{2}+h_{3}=697.83$

$\mathrm{P}=0.54 \mathrm{ksi}, 1 \mathrm{ksi}=1450$ ton $/ \mathrm{mm}^{2}$

3-Cycle Friction, $\mu=0.122-0.01 \mathrm{P}, \mu=0.116$

Adjust for high velocity $=-0.036=0.116-0.036$

$=0.078$ (Lower bound friction)

I-cycle friction $\mu=1.2 \times 0.078=0.093$

Lowerbound $\mu_{2}=\mu_{3}=0.078$

Upper bound $\mu_{2}=\mu_{3}=0.093$

$\mu=$ force at zero displacement divided by the normal load

For Lower Bound,

$\mu=\mu_{1}-\left(\mu_{1}-\mu_{2}\right) \times\left(R_{2 \text { eff }} / R_{1 \text { eff }}\right), \mu=0.083$

For Upper Bound,

$\mu=\mu_{1}-\left(\mu_{1}-\mu_{2}\right) \times\left(R_{2 \text { eff }} / R_{1 \text { eff }}\right), \mu=0.100$

\subsection{Calculating $D_{d}$ (Upper bound Analysis)}

$$
\begin{aligned}
& S_{d}=1.13 \quad \mu=0.100 \\
& \mu_{l}=0.093 D_{y}=0.0424 \quad W=2295.5 \text { ton } \\
& F_{d}=1.01 \quad=2 \\
& \text { No. of bearing }=2 \\
& \Sigma F_{d}=F_{d} \times W \times \text { Total Bearing }=1.01 \times 2295.5 \times 2 \\
& \Sigma F_{d}=4636.91 \\
& \Sigma W=V k \text { Load } \times \text { No. of bearing } \Sigma W=4591 \text { ton } \\
& \text { Let the displacement be } \mathrm{D}_{\mathrm{d}}=0.4306 \mathrm{~m} \\
& \text { Effective Stiffness, } Q_{d}=\mu \times \Sigma W \\
& \mathrm{Q}_{\mathrm{d}}=381.05 \text { ton }
\end{aligned}
$$


$K_{D}=\Sigma F_{d} / D_{d}=4636.91 / 0.4306 \quad \mathrm{~K}_{\mathrm{D}}=10768.48$ ton $/ \mathrm{m}$

$K_{\text {eff }}=k_{D}+Q_{D} / D_{D}=10768.48+381.05 / 0.4306$

$K_{\text {eff }}=11653.41$ ton $/ \mathrm{m}$.

Effective period, - refer Eq. 17.5-2, ASCE 7-10

$T_{\text {eff }}=2 \pi \sqrt{ }((\Sigma w) /($ Keff $\times g)) T_{\text {eff }}=2.5 \mathrm{sec}$.

Effective damping, - refer Eq. 17.8-7, ASCE 7-10

$\beta_{d}=E /\left(2 \pi K_{\text {eff }} D_{d} 2 \quad \beta_{\text {eff }}=\beta_{d}=0.0525\right.$ or $5.25 \%$

Damping Reduction Factor,

$\beta=\left(\beta_{\text {eff }} / 0.05\right)^{0.3} \beta=1.0147$

$D_{d l}=\left(S_{d} \times T_{e f}^{2} g\right) /\left(4 \pi^{2} \beta\right), D_{d l}=0.4326 \mathrm{~m}$

\subsection{Calculating Sap2000 links/support property data (Upper Bound)}

Main Properties

Determination of Bearing (Rotational Inertia)

Diameter $\varphi=0.305 \mathrm{~m}$ with height $\mathrm{h}=0.32 \mathrm{~m}$ (Total height of the bearing)

It had been considered that the isolator is a cylinder with $\varphi=0.484 \mathrm{~m}, h=0.5 \mathrm{~m}$.

Then $\mathrm{C} / \mathrm{s}$ Area $A=\left(\pi \varphi^{2}\right) / 4=0.1840 \mathrm{~m}^{2}$

$K_{\text {eff }}=\left(W / R_{\text {leff }}\right)+\left(\mu \times W / D_{d}\right) \mathrm{K}_{\text {eff }}=650.29$ ton $/ \mathrm{m}$

$I=\left(K_{\text {eff }} \times h^{3}\right) / 12 E=\left(650.29 \times 0.5^{3}\right) / 12$

$=6.77 \mathrm{E}-07 \mathrm{~m}^{4}$

$E=1.00 \mathrm{E}+07 \mathrm{~N} / \mathrm{mm}^{2}$.

Determine of bearing mass

$D_{m-\max }=0.4326 \mathrm{~m}$.

$D_{T M}=1.15 \times 0.4326$ refer $($ Eq. 17.5.3.5 - ASCE 7-10)

$D_{T M}=0.4974 \mathrm{~m}$.

$D=2 D_{T M}=2 \times 0.4974 \quad D=0.16146 \mathrm{~m}$.

$W=0.241 D^{2}-0.0564 D \quad \mathrm{w}=0.182393$ ton.

$m=W / g=0.182393 / 9.8 \mathrm{~m}=0.0185925$ ton $\mathrm{sec}^{2} / \mathrm{m}$.

\subsection{Directional Properties (U2 - U3)}

Linear properties

Effective stiffness $K_{\text {eff }}=650.29$ ton $/ \mathrm{m}$

Effective damping $\beta_{\text {eff }}=0.0525$ or $5.25 \%$

Height for outer surface, $=h_{1}=h_{4}=936.56 \mathrm{~mm}$.

Height for outer surface, $=h_{2}=h_{3}=697.83 \mathrm{~mm}$

Non-linear properties

Stiffness $=\mu_{1} W / D_{y}, R_{2 e f f}=3030 \mathrm{~mm}$ or $3.030 \mathrm{~m}$

$D_{y}=\left(\mu_{1}-\mu_{2}\right) R_{2 e f f}=(0.102-0.093) * 3.030$

$D_{\mathrm{y}}=0.02727 \mathrm{~m}$.

Stiffness of outer surface $=\mu_{1} W / D_{y}$ $=(0.102 \times 2295.5) / 0.02727=5116.426$ ton $/ \mathrm{m}$

Stiffness of inner surface $=\mu_{2} W / D_{y}$

$=(0.093 \times 2295.5) / 0.02727=7828.43 \mathrm{ton} / \mathrm{m}$

Friction slow $=\mu_{1}$ for outer surface $=0.102$

Friction slow $=\mu_{l}$ for Inner surface $=0.093$

Friction fast $=2 \times \mu_{1}$ for outer surface $=0.204$

Friction fast $=2 \times \mu_{1}$ for outer surface $=0.186$

Rate Parameter $=$ Friction slow $/$ Friction fast 
$=0.102 / 0.204=0.5$

* Radius of sliding surface

For outer $=R_{\text {leff }}=19.585 \mathrm{~m}$.

For inner $=R_{\text {eeff }}=3.030 \mathrm{~m}$.

* Stop distance

For outer surface $u_{1} *=2 D_{y}+2 d_{1} *=6.290 \mathrm{~m}$.

For outer surface $u_{2}^{*}=2 D_{y}=0.05454 \mathrm{~m}$.

\section{Numerical Study}

The seismic response of elevated steel storage tank isolated with TFPS is compared with FPS for California Imperial valley (El Centro array\#5) earthquake on October 15, 1979. Different criteria's for elevated tank have taken from the paper [4]. For elevated tank, damping ratio of convective mass has been taken $0.5 \%$ and impulsive mass has been considered as $2 \%$. The tank wall is prepared from steel having mass density $\varrho_{s}=7900 \mathrm{~kg} / \mathrm{m}^{3}$, and modulus of elasticity $E=200 \mathrm{GPA}$. The response quantities of concentration are tower displacement $\mathrm{x}_{\mathrm{t}}$ base shear $F_{\mathrm{b}}(\mathrm{W})$, sloshing mass $x_{\mathrm{c}}$, isolation system, and impulsive mass, $x_{\mathrm{i} .}$ The Time variation of $\mathrm{x}_{\mathrm{t}}, \mathrm{F}_{\mathrm{b}}(\mathrm{W}), \mathrm{x}_{\mathrm{c}}, \mathrm{x}_{\mathrm{b}}$, and $\mathrm{x}_{\mathrm{i}}$ for slender tank isolated with FPS and TFPS is shown in Fig.2. The values for the two types of friction base isolators FPS $\left(T_{\mathrm{b}}\right.$ $=2.5 \mathrm{~s}$ and $\mu=0.1)$, and TFPS $\left(T_{\mathrm{b}}=2.5 \mathrm{~s}\right.$ and $\left.\mu=0.1\right)$ are taken for comparison of the seismic response. Fig 2 indicates that there is significant reduction in $\mathrm{F}_{\mathrm{b}}(\mathrm{W}), \mathrm{x}_{\mathrm{c}}$ and $\mathrm{x}_{\mathrm{b}}$, of tank isolated with TFPS as compared to FPS. Impulsive movement is almost identical in both isolators. The peak values of tower displacement, base shear, sloshing displacement, isolator displacement and impulsive displacement for FPS and TFPS are $12.2 \mathrm{~mm}$ and $7.8 \mathrm{~mm}, 0.15$ and $0.13 \mathrm{~W}, 3204.8$ and $2706.5 \mathrm{~mm}, 420.1$ and $283.4 \mathrm{~mm}$ and 1.3 and $1.4 \mathrm{~mm}$.

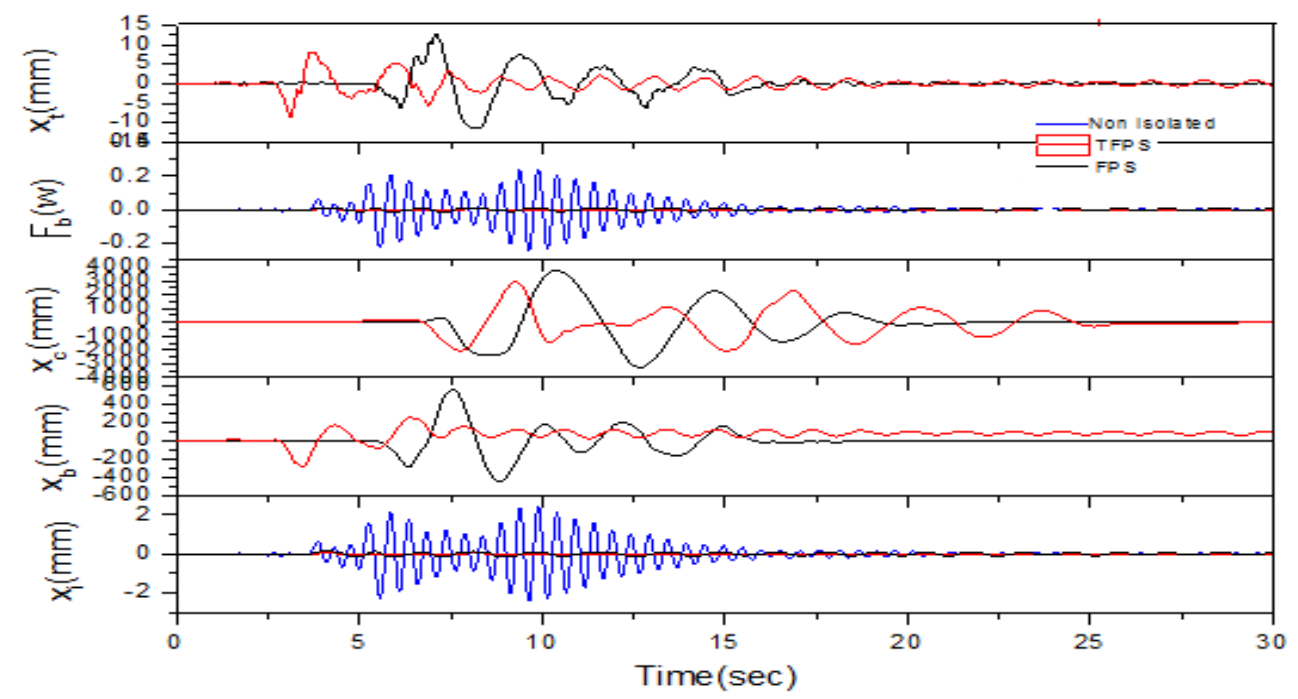

Figure 2Time variation of $\mathrm{x}_{\mathrm{t}}, \mathrm{F}_{\mathrm{b}}(\mathrm{W}), \mathrm{x}_{\mathrm{c}}, \mathrm{x}_{\mathrm{b}}$, and $\mathrm{x}_{\mathrm{i}}$ displacement of slender tank isolated with FPS $\left(\mathrm{T}_{\mathrm{b}}=2.5 \mathrm{~s}\right.$ and $\mu=0.1)$ and TFPS $\left(T_{b}=2.5 \mathrm{~s}\right.$ and $\left.\mu=0.1\right)$ under Imperial Valley, 1979(ElCentroArray\#5) earthquake ground motion 


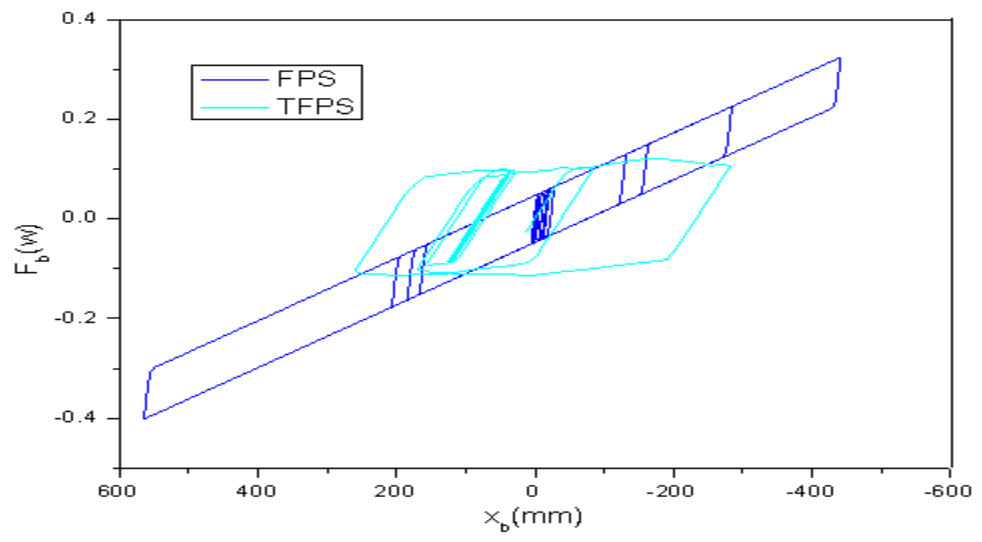

Figure 3Isolator displacement variation of base shear of liquid storage tank isolated with FPS $\left(\mathrm{T}_{\mathrm{b}}=2.5 \mathrm{sec}\right.$ and FPS $\mu=0.1$ ) and TFPS ( $\mathrm{T}_{\mathrm{b}}=2.5 \mathrm{~s}$ and $\mu=0.1$ ) under Imperial Valley, 1979 (El Centro Array \#5) earthquake ground motion

\section{Conclusions}

Detail study has conducted to check the effectiveness of TFPS in elevated liquid steel storage tank. For this current, study two types of sliding systems namely FPS and TFPS.

- During earthquake excitation sloshing displacement, base shear, and isolator displacement can be controlled more effectively by TFPS rather than FPS

- Impulsive displacement and tower displacement are not affected more by application of different isolation system.

\section{References}

M.K.Shrimali, R. (2002). Non-linear seismic response of base-isolated liquid storage tanks to bidirectional excitation. Nuclear Engineering and Design, Vol.217, pp. 1-20.

Mohamed, A. A. (2011). Seismic analysis and modeling of isolated elevatedliquid storage tanks. Earthquakes and Structures, Vol. 2 , 397-412.

R. A. Livaoglua, A. B. (2006). 2006 Simplified seismic analysis procedures for elevated tanks considering fluid-structure-soil interaction. Journal of Fluids and Structures, Vol. 22 , 421-439.

V. R. Panchal, R. S. (2007). Variable friction pendulum system for seismic isolation of liquid storage tanks, . Nuclear Engineering and Design, Vol. 238 , 1304-1315.

V. R. Panchal, R. S. (2012). Behavior of liquid storage tanks with VCFPS under near-fault ground motions. Structure and Infrastructure Eng., Vol. 8 , 71-88.

V. R. Panchal., R. S. (2008). Variable friction pendulum system for near-fault ground motions for seismic isolation of liquid storage tanks. Structural Control and Health Monitoring, Vol. 15 , 568584. 